\title{
Label-Free Time-Gated Luminescent Detection Method for the Nucleotides with Varying Phosphate Content
}

\author{
Kari Kopra ${ }^{1, *(D)}$, Tanja Seppälä ${ }^{1}$, Dana Rabara ${ }^{2}$, Maria Abreu-Blanco ${ }^{2}$, Sakari Kulmala ${ }^{3}$, \\ Matthew Holderfield ${ }^{2}$ and Harri Härmä ${ }^{1}$ \\ 1 Materials Chemistry and Chemical Analysis, University of Turku, Vatselankatu 2, 20500 Turku, Finland; \\ tatese@utu.fi (T.S.); harri.harma@utu.fi (H.H.) \\ 2 NCI-RAS Initiative, Cancer Research Technology Program, Frederick National Laboratory for Cancer \\ Research, Leidos Biomedical Research, Frederick, MD 21702, USA; dana.rabara@nih.gov (D.R.); \\ maria.abreublanco@nih.gov (M.A.-B.); matthew.holderfield@nih.gov (M.H.) \\ 3 Laboratory of Analytical Chemistry, Department of Chemistry, Aalto University, P.O. Box 16100, \\ 00076 Aalto, Finland; sakari.kulmala@aalto.fi \\ * Correspondence: khkopr@utu.fi
}

Received: 3 October 2018; Accepted: 12 November 2018; Published: 16 November 2018

\begin{abstract}
A new label-free molecular probe for luminescent nucleotide detection in neutral aqueous solution is presented. Phosphate-containing molecules, such as nucleotides possess vital role in cell metabolism, energy economy, and various signaling processes. Thus, the monitoring of nucleotide concentration and nucleotide related enzymatic reactions is of high importance. Two component lanthanide complex formed from $\mathrm{Tb}$ (III) ion carrier and light harvesting antenna, readily distinguishes nucleotides containing different number of phosphates and enable direct detection of enzymatic reactions converting nucleotide triphosphate (NTP) to nucleotide di/monophosphate or the opposite. Developed sensor enables the detection of enzymatic activity with a low nanomolar sensitivity, as highlighted with K-Ras and apyrase enzymes in their hydrolysis assays performed in a high throughput screening compatible 384-well plate format.
\end{abstract}

Keywords: nucleotide triphosphate; label-free; K-Ras; apyrase; terbium

\section{Introduction}

Phosphate-containing molecules such as nucleotides have vital roles in living cells. ATP is the universal energy molecule and signal mediator, while the main function of GTP is in signaling and it has only a secondary role in energy transduction [1-3]. Other nucleotide triphosphates (NTPs) have more specified roles in various enzymatic reaction, DNA synthesis, replication, and cell division [4,5]. For these reasons, there has been continuous interest in nucleotide sensors, especially for ATP sensing [6-9]. During recent years, nucleotide sensors based on chromatographic methods, bioluminescence, and luminescence have been developed [6-10]. These methods have a large variation in sensitivity, simplicity, and robustness. For NTP sensing, bioluminescence methods based on luciferin-luciferase reaction are currently the method of choice mostly due to the high sensitivity [9].

Luminescent molecular probes are widely used in academia and industry, meeting the needs for affordable, non-radioactive, and simple tools also suitable for high throughput screening (HTS) applications [11]. Lanthanide ions, such as $\mathrm{Eu}(\mathrm{III})$ and $\mathrm{Tb}(\mathrm{III})$, are poorly luminescent, but in combination with protective chelating structure and light harvesting antenna, these metal complexes have an intense long-lived millisecond scale luminescence [12]. Luminescence of such metal complex probes can be readily modulated through the environment and complex forming agents often leading 
to luminescence quenching. This property has been reported to enable detection of various targets such as food, steroids, and biologically significant nucleotides [13-17]. Label-free sensors provide the simplest tool for the detection of phosphate-containing molecules e.g., nucleotides. Label-free assays can be performed without specific binding reagent, such as aptamer or antibody, but these methods are often limited in sensitivity and also possess poor functionality in neutral aqueous solutions [18]. Lanthanide-based methods have also been rarely developed and validated to study phosphate-containing molecules in real biochemical environment, reducing the applicability of the methods.

We have previously described antibody-based nucleotide detection system for GTP and cAMP using single-label technique called quenching resonance energy transfer (QRET) [19-23]. Nucleotide detection using antibodies is limited to the affinity of the antibody and detection of multiple different nucleotides requires the usage of different antibodies. Here, we present a label- and antibody-free two-component luminescent terbium(III)-probe for nucleotide triphosphate detection. Sensor forming from two individually non-luminescent parts enables nucleotide triphosphate separation from diand monophosphates with nanomolar sensitivity in real biochemical context. The functionality of the presented assay was studied in a K-Ras GTP hydrolysis system, performing side-by-side comparison with the specific GTP detection assay utilizing the QRET technique [22,23]. The method was further used in enzymatic apyrase assay, monitoring its hydrolysis activity with ATP and multiple other nucleotides.

\section{Materials and Methods}

\subsection{Materials}

All used phosphate containing molecules (ATP, ADP, AMP-PNP, CTP, cAMP, cGMP, GTP, GDP, GMP, ITP, UTP, UDP, and sodium poly-, tri-, di-, and monophosphates), antenna ligands; antenna 1 (4-hydroxy-6-(trifluoromethoxy)-quinoline-3-carboxylic acid), antenna 2 (4-hydroxy-7-methyl-1,8naphtyridine-3-carboxylic acid), antenna 3 (1-cyclopropyl-6-fluoro-4- oxo-7-piperazin-1-yl quinoline-3carboxylic acid), antenna 4 (1-ethyl-1,4-dihydro-7-methyl-4-oxo-1,8-naphthyridine-3-carboxylic acid), antenna 5 (2-methyl-7-oxo-4,7- dihydropyrazolo[1,5-a]pyrimidine-6-carboxylic acid), and antenna 6 (4-oxo-1,4-dihydroquinoline-3-carboxylic acid), $\mathrm{TbCl}_{3}$, apyrase (A6410), and DCAI (2-(4,6-dichloro-2methyl-1h-indol-3-yl)ethanamine) were purchased from Sigma-Aldrich (St. Louis, MO, USA). Diethylenetriamine- $\mathrm{N}^{1}, \mathrm{~N}^{2}, \mathrm{~N}^{3}, \mathrm{~N}^{3}$-tetraacetic acid $\mathrm{Tb}$ (III)-chelate ( $\mathrm{Tb}$ (III)-N1-chelate) was obtained from PerkinElmer Life and Analytical Sciences, PerkinElmer Wallac (Turku, Finland). All K-Ras (res. 2-188) proteins (wild-type, G12C, G12D, Q61L, and Q61R), His-SOS ${ }^{\text {cat }}$ (res. 564-1049), p120GAP (res. 714-1047), and NF1-333 (res. 1198-1530) were of human origin and produced in E. coli [21-23]. Eu(III)-GTP was synthetized and conjugated as described elsewhere [22-24]. The soluble quencher molecule, MT2, was obtained from QRET Technologies (Turku, Finland), and used according to manufacturer's instruction. 2A4 ${ }^{\mathrm{GTP}}$ Fab fragment selection, production, and purification are described elsewhere [23,24]. Black Corning 384 well low volume assay plates (4513) were used in all assays. The small molecule library used was randomly selected part of the DIVERSet ${ }^{\mathrm{TM}}$ ChemBridge Diverse Screening Library. Assays were performed in selected assay buffer 1 (20 mM HEPES, pH 7.5, $1 \mathrm{mM} \mathrm{MgCl} 2,0.01 \%$ Triton-X 100, 0.005\% $\gamma$-globulins) if not otherwise mentioned. Apyrase assays were performed in assay buffer $2(20 \mathrm{mM}$ HEPES, $\mathrm{pH} 6.5,1 \mathrm{mM}$ $\mathrm{MgCl}_{2}, 1 \mathrm{mM} \mathrm{CaCl} 2,0.01 \%$ Triton-X 100, 0.005\% $\gamma$-globulins).

\subsection{Instrumentation}

The Eu(III)-GTP purification was carried out using reversed-phase adsorption chromatography, Dionex ultimate 3000 LC system from Thermo Fischer Scientific, Dionex (Sunnyvale, CA, USA), and Ascentis RP-amide C18 column from Sigma-Aldrich, Supelco Analytical. Time-gated luminescence for $\mathrm{Eu}(\mathrm{III})$-chelate was monitored using $615 \mathrm{~nm}$ emission and $340 \mathrm{~nm}$ excitation wavelengths, and $600 \mu$ s delay and $400 \mu$ s decay times. Time-gated luminescence for $\mathrm{Tb}(\mathrm{III})$-probes were monitored 
using $545 \mathrm{~nm}$ emission and $330 \mathrm{~nm}$ excitation wavelengths, $100 \mu$ s delay, and $200 \mu$ s decay times. All measurements were performed using a standard microtiter plate reader developed by Labrox Ltd. (Turku, Finland). Pre-plating of the library compounds was performed with an Echo 550 Liquid Handler (Labcyte Inc., San Jose, CA, USA). Emission and excitation spectrums were measured using Varian Cary Eclipse fluorescence spectrophotometer (Agilent Technologies, Mulgrave, Australia). Luminescence excitation spectra's (220-400 nm) for Tb(III)-N1-chelate and Probe 1 were monitored with $5 \mathrm{~nm}$ slit, $545 \mathrm{~nm}$ emission with $10 \mathrm{~nm}$ slit, $100 \mu$ s delay, and $100 \mu$ s decay. Luminescence emission spectra (450-700 nm) for Probe 1 was monitored with $5 \mathrm{~nm}$ slit, $330 \mathrm{~nm}$ excitation with $10 \mathrm{~nm}$ slit, $100 \mu \mathrm{s}$ delay, and $100 \mu \mathrm{s}$ decay. The emission spectra for $\mathrm{Tb}(\mathrm{III})$-N1-chelate was monitored similarly as for Probe 1, but using $240 \mathrm{~nm}$ excitation. Emission lifetime for Probe 1 was monitored using $330 \pm 20 \mathrm{~nm}$ excitation and $545 \pm 20 \mathrm{~nm}$ emission wavelengths.

\subsection{Probe 1 Selection}

Preselected antennas (antenna 1 to 6 ) were first tested with $\mathrm{TbCl}_{3}$ and $\mathrm{Tb}$ (III)-N1 (2.5-50 nM) in various antenna concentrations $(1-100 \mu \mathrm{M})$. All assays were performed in $10 \mu \mathrm{L}$ final volume. Using $10 \mu \mathrm{M}$ GTP $(5 \mu \mathrm{L})$ as an analyte, we defined maximal signal-to-background (S/B) and signal stability with antennas 1 to $6(7.5 \mu \mathrm{M})$, either with $\mathrm{TbCl}_{3}(7.5 \mathrm{nM})$ or $\mathrm{Tb}(\mathrm{III})-\mathrm{N} 1(7.5 \mathrm{nM})$ added as a preformed complex with different antennas $(5 \mu \mathrm{L})$. $\mathrm{Tb}(\mathrm{III})-\mathrm{N} 1$ in complex with all the antennas was further used to perform single concentration $(750 \mathrm{nM})$ nucleotide triphosphate (NTP) assay (GTP, ATP, ITP, UTP, and CTP), and thereafter nucleotide titration $(0.5-32,000 \mathrm{nM})$ using various phosphate containing analytes (ATP, ADP, AMP-PNP, CTP, cAMP, cGMP, GTP, GDP, GMP, ITP, UTP, UDP, and sodium poly-, tri-, di-, and monophosphates). Signal stability was monitored performing multiple measurements between $5 \mathrm{~min}$ and $120 \mathrm{~min}$. Based on these experiments, we selected antenna 1 (4-hydroxy-6-(trifluoromethoxy)quinoline-3-carboxylic acid) to form the complex with $\mathrm{Tb}(\mathrm{III})-\mathrm{N} 1$ (Probe 1).

$\mathrm{Tb}(\mathrm{III})-\mathrm{N} 1$-chelate alone and Probe 1 were further characterized by measuring luminescence spectra in assay buffer 1 (pH 7.5) in the presence of 0-100 $\mu \mathrm{M}$ GTP and with the parameters listed above. Thereafter Probe 1 was monitored in a modified assay buffer $1(\mathrm{pH} 6-8)$ and in the presence or absence of $10 \mu \mathrm{M}$ ATP in $500 \mu \mathrm{L}$ volume.

Probe 1 tolerance for different small molecular ligands was tested using 320 randomly selected library compounds transferred into the assay plates from $10 \mathrm{mM}$ stock solutions (final concentration $20 \mu \mathrm{M}$ ). Assay plate was complemented with 64 dimethyl sulfoxide (DMSO) controls without compound. Full plate was assayed with GTP $(1.5 \mu \mathrm{M})$ and without GTP in $10 \mu \mathrm{L}$ final volume and the $Z^{\prime}$-factors were calculated.

\subsection{Label-Free K-Ras Activity Assays}

Probe 1 was used in K-Ras (wild-type and four mutants) GTPase cycling assay to monitor GTP hydrolysis. The GTPase cycling assays, 200 nM K-Ras (wild-type, and G12C, G12D, Q61L, and Q61R mutants), SOS ${ }^{\text {cat }}(200 \mathrm{nM})$, p120RasGAP or NF1 $(100 \mathrm{nM})$, GTP $(1.5 \mu \mathrm{M})$, were performed in a 384-well plate using $5 \mu \mathrm{L}$ volume (Table 1). After 60 min hydrolysis reaction, the detection was performed using Probe 1 in a $10 \mu \mathrm{L}$ final volume. $\mathrm{Tb}(\mathrm{III})$-signal was monitored at multiple time points (10-90 min). DCAI titration $(1.25-500 \mu \mathrm{M})$ was performed using $200 \mathrm{nM}$ K-Ras (wild-type or Q61R mutant), SOS ${ }^{\text {cat }}$ $(200 \mathrm{nM}), \mathrm{p} 120 \mathrm{RasGAP}(100 \mathrm{nM})$, and GTP $(1.5 \mu \mathrm{M})$. DCAI was added in $1 \mu \mathrm{L}$ volume ( $2 \%$ DMSO in final volume) and $60 \mathrm{~min}$ hydrolysis reaction was performed in $5 \mu \mathrm{L}$ volume as previously. After incubation, hydrolysis was monitored using Probe 1 in a $10 \mu \mathrm{L}$ final volume and the time-gated $\mathrm{Tb}$ (III)-luminescence signal was monitored as previously. The reproducibility of the GTPase cycling assay was confirmed using K-Ras wild-type and comparing it to K-Ras mutants G12D and Q61R. Assay was performed using 24 replicate reactions supplemented with SOS ${ }^{\text {cat }}$ and p120RasGAP. Tb(III)-signals were measured $60 \mathrm{~min}$ after Probe 1 addition, reaching the $10 \mu \mathrm{L}$ final volume. Results were used to calculate Z'-factor. 
We subsequently performed GTP association assay using $500 \mathrm{nM}$ K-Ras (wild-type, G12C, and Q61R), SOS ${ }^{\text {cat }}(250 \mathrm{nM})$, and GTP (500 nM) (Table 1). Association was performed in $6 \mu \mathrm{L}$ volume, and after $20 \mathrm{~min}$ incubation, the detection was performed using Probe 1 (10 $\mu \mathrm{L}$ final volume). Similarly, DCAI titration (1.25-500 $\mu \mathrm{M})$ was performed using $500 \mathrm{nM}$ K-Ras (wild-type or Q61R mutant), SOS ${ }^{\text {cat }}$ $(250 \mathrm{nM})$, and GTP $(500 \mathrm{nM})$ in $7 \mu \mathrm{L}$ volume. DCAI was added in $1 \mu \mathrm{L}$ volume ( $\%$ DMSO in final volume). Probe 1 was added in $3 \mu \mathrm{L}$ to reach the final $10 \mu \mathrm{L}$ volume. In both assays, time-gated $\mathrm{Tb}$ (III)-signals were monitored at multiple time points between $10 \mathrm{~min}$ and $90 \mathrm{~min}$.

Table 1. Summarized K-Ras GTPase cycling and GTP association and apyrase ATPase assay components.

\begin{tabular}{|c|c|c|c|c|}
\hline Method & Detection & Reaction & Assay Buffer & Measurement \\
\hline $\begin{array}{l}\text { GTPase } \\
\text { cycling assay }\end{array}$ & $\begin{array}{l}\text { Probe 1: } 7.5 \mu \mathrm{M} \\
\text { antenna 1,7.5 nM } \\
\text { Tb(III)-N1 } \\
\text { QRET: } 7.5 \mathrm{nM} \\
\text { Eu(III)-GTP, } 12 \mathrm{nM} \\
\text { 2A4 GTP Fab, } \\
\text { 1.8 } \mu \text { M MT2 }\end{array}$ & $\begin{array}{l}200 \text { nM K-Ras, } \\
200 \text { nM SOS } \\
100 \text { nM GAP } \\
\text { (p120RasGAP or } \\
\text { NF1), } 1.5 \mu \mathrm{M} \text { GTP }\end{array}$ & $\begin{array}{l}\text { Buffer 1: } 20 \mathrm{mM} \mathrm{HEPES,} \\
\text { pH 7.5, } 1 \mathrm{mM} \mathrm{MgCl} \\
0.01 \% \text { Triton-X 100, } 0.005 \% \\
\gamma \text {-globulins }\end{array}$ & $\begin{array}{l}\text { Probe 1: } 330 / 545 \mathrm{~nm} \\
\text { Tb(III)-luminescence } \\
(10 \mu \mathrm{L}) \\
\text { QRET: } 340 / 615 \mathrm{~nm} \\
\text { Eu(III)-luminescence } \\
(10 \mu \mathrm{L})\end{array}$ \\
\hline $\begin{array}{l}\text { GTP } \\
\text { association } \\
\text { assay }\end{array}$ & $\begin{array}{l}\text { Probe 1: } 7.5 \mu \mathrm{M} \\
\text { antenna 1, } 7.5 \mathrm{nM} \\
\text { Tb(III)-N1 } \\
\text { QRET: } 10 \mathrm{nM} \\
\text { Eu(III)-GTP, } 1.5 \mu \mathrm{M} \\
\text { MT2 }\end{array}$ & $\begin{array}{l}500 \text { nM K-Ras, } \\
250 \text { nM SOS }{ }^{\text {cat }}, \\
500 \text { nM GTP } \\
200 \text { nM K-Ras, } \\
200 \text { nM SOS }{ }^{\text {cat }},\end{array}$ & $\begin{array}{l}\text { Buffer 1: } 20 \mathrm{mM} \mathrm{HEPES,} \\
\text { pH 7.5, } 1 \mathrm{mM} \mathrm{MgCl} \mathrm{Mg}_{2} \\
0.01 \% \text { Triton-X 100, } 0.005 \% \\
\gamma \text {-globulins }\end{array}$ & $\begin{array}{l}\text { Probe 1: } 330 / 545 \mathrm{~nm} \\
\text { Tb(III)-luminescence } \\
(10 \mu \mathrm{L}) \\
\text { QRET: } 340 / 615 \mathrm{~nm} \\
\text { Eu(III)-luminescence } \\
(10 \mu \mathrm{L})\end{array}$ \\
\hline $\begin{array}{l}\text { Apyrase } \\
\text { assay }\end{array}$ & $\begin{array}{l}\text { Probe } 1: 7.5 \mu \mathrm{M} \\
\text { antenna } 1,7.5 \mathrm{nM} \\
\mathrm{Tb}(\mathrm{III})-\mathrm{N} 1\end{array}$ & $\begin{array}{l}50 \mu \mathrm{U} \text { apyrase, } \\
1-10 \mu \mathrm{M} \text { ATP }\end{array}$ & $\begin{array}{l}\text { Buffer 2: } 20 \mathrm{mM} \mathrm{HEPES} \\
\text { pH } 6.5,1 \mathrm{mM} \mathrm{MgCl}_{2}, \\
1 \mathrm{mM} \mathrm{CaCl} 2,0.01 \% \\
\text { Triton-X } 100,0.005 \% \\
\gamma \text {-globulins }\end{array}$ & $\begin{array}{l}\text { Probe 1: } 330 / 545 \mathrm{~nm} \\
\text { Tb(III)-luminescence } \\
(10 \mu \mathrm{L})\end{array}$ \\
\hline
\end{tabular}

\subsection{QRET-Based Control Assay for GTPase Cycling and GTP Association Monitoring}

The competitive QRET based GTPase cycling assay was used as a control for the assay performed with Probe 1 [23]. Assays with K-Ras wild-type and mutants (G12C, G12D, Q61L, and Q61R) were performed using same assay conditions listed above and used in case of Probe 1 (Table 1). Enzymatic assays were performed in $5 \mu \mathrm{L}$, and time-gated Eu(III)-signals were monitored after QRET detection component (7.5 nM Eu(III)-GTP, $12 \mathrm{nM} 24_{4}^{\mathrm{GTP}}$, and $1.8 \mu \mathrm{M}$ MT2) addition (10 $\mu \mathrm{L}$ total volume). In DCAI titration $(1.25-500 \mu \mathrm{M})$ the DMSO concentration was $2 \%$ in final $10 \mu \mathrm{L}$ volume. Time-gated $\mathrm{Eu}(\mathrm{III})$-signal was monitored at multiple time points between $10 \mathrm{~min}$ and $90 \mathrm{~min}$.

The Eu(III)-GTP association assay was used as a control assay for label-free GTP association detection using Probe 1 [22]. Eu(III)-GTP association assay was performed in $10 \mu \mathrm{L}$ volume using 200 nM K-Ras (wild-type, and mutants G12C, G12D, Q61L, and Q61R), SOS ${ }^{\text {cat }}$ (200 nM), Eu(III)-GTP $(10 \mathrm{nM})$, and MT2 $(1.5 \mu \mathrm{M})$ (Table 1). All components were added in $2.5 \mu \mathrm{L}$ volumes and Eu(III)-signals were monitored between $10 \mathrm{~min}$ and $90 \mathrm{~min}$. In DCAI titration $(1.25-500 \mu \mathrm{M})$ the same protocol was applied and the DMSO concentration was $2 \%$ in the final $10 \mu \mathrm{L}$ volume.

\subsection{Label-Free Apyrase ATPase Activity Monitoring}

Probe 1 was used in ATP hydrolysis monitoring using potato apyrase (ATPase) as a model enzyme. Apyrase assay was performed in assay buffer 2, which was supplemented with $1 \mathrm{mM} \mathrm{Ca}^{2+}(\mathrm{pH}$ 6.5) (Table 1). First, the apyrase ATPase activity was titrated with 1 or $10 \mu \mathrm{M}$ ATP or $10 \mu \mathrm{M}$ AMP-PNP in a $5 \mu \mathrm{L}$ reaction. After 50 min incubation, the detection was performed using Probe $1(10 \mu \mathrm{L}$ final volume). $\mathrm{Tb}(\mathrm{III})$-signals were monitored at multiple time points between $10 \mathrm{~min}$ and $60 \mathrm{~min}$. After apyrase titration, the apyrase specificity was tested with the panel of NTPs (ATP, GTP, UTP, CTP, and AMP-PNP) and NDPs (ADP, GDP, and UDP). NTP (10 $\mu \mathrm{M})$ hydrolysis was performed using $50 \mu \mathrm{U}$ of apyrase, and with NDPs $(50 \mu \mathrm{M})$ the used apyrase concentration was $200 \mu \mathrm{U}$. After 50 min 
incubation in $5 \mu \mathrm{L}$ volume, Probe 1 was added and the time-gated $\mathrm{Tb}(\mathrm{III})$-signal was monitored at multiple time points between $10 \mathrm{~min}$ and $60 \mathrm{~min}$.

\subsection{Data Analysis}

In all assays, the signal-to-background ratio (S/B) was calculated as $\mu_{\max } / \mu_{\min }$, coefficient of variation $(C V \%)(\sigma / \mu) \times 100$, and $Z^{\prime}$-factor $\left(1-\left[\left(3 \sigma_{\max }+3 \sigma_{\min }\right) /\left(\left|\mu_{\max }-\mu_{\min }\right|\right)\right]\right)$. In all formulas $\mu$ is the mean value, and $\sigma$ is the standard deviation. All data was analyzed using Origin 8 software (OriginLab, Northampton, MA, USA).

\section{Results and Discussion}

Phosphate-containing molecules, e.g., nucleotides, play important roles in variety of biological processes [1-5]. Nucleotides are involved in energy metabolism and several enzymatic reactions, and the simplest way to efficiently study these reactions is to monitor changes in concentration of nucleotides with varying phosphate content. To address this, we developed label-free sensor for enzymatic nucleotide studies.

\subsection{Label-Free Terbium(III)-Probe Enables Nanomolar Detection of Phosphate-Containing Molecules}

First, we selected functional terbium(III)-probe enabling phosphate content based separation of the studied molecules in neutral $\mathrm{pH}$. The ion carrier (diethylenetriaminetetraacetic acid) is in a stable complex with $\mathrm{Tb}$ (III) forming $\mathrm{Tb}(\mathrm{III})$-N1-chelate, which is itself incapable to sensitize the $\mathrm{Tb}$ (III)-luminescence without the antenna ligand, when $330 \mathrm{~nm}$ excitation light is used (Figure S1). With antenna, formed chelate-ligand complex gave the characteristic $\mathrm{Tb}$ (III) luminescence and luminescence lifetime of $590 \pm 4 \mu \mathrm{s}$, enabling $330 \mathrm{~nm}$ excitation and time-gated measurements at the $\mathrm{Tb}(\mathrm{III})$ main peak of $545 \mathrm{~nm}$ in $\mathrm{pH}$ range from 6 to 8 (Figure 1, Figure S2). The $\mathrm{Tb}(\mathrm{III})$-ion is strongly coordinated to the carrier ligand by seven donor atoms providing two coordination sites for the light harvesting antenna [25]. Phosphate-containing molecules can readily compete the antenna and occupy the two remaining coordination sites (Figure 1). In the presence of phosphate-containing nucleotide, competition between nucleotide and the antenna ligand induce the luminescence quenching, when antenna is displaced from the Probe 1 complex by phosphates of the nucleotide [26]. These interactions occur efficiently in neutral or slightly acidic buffer conditions, ideal for the most of the biologically relevant reactions (Figure S2). 
A

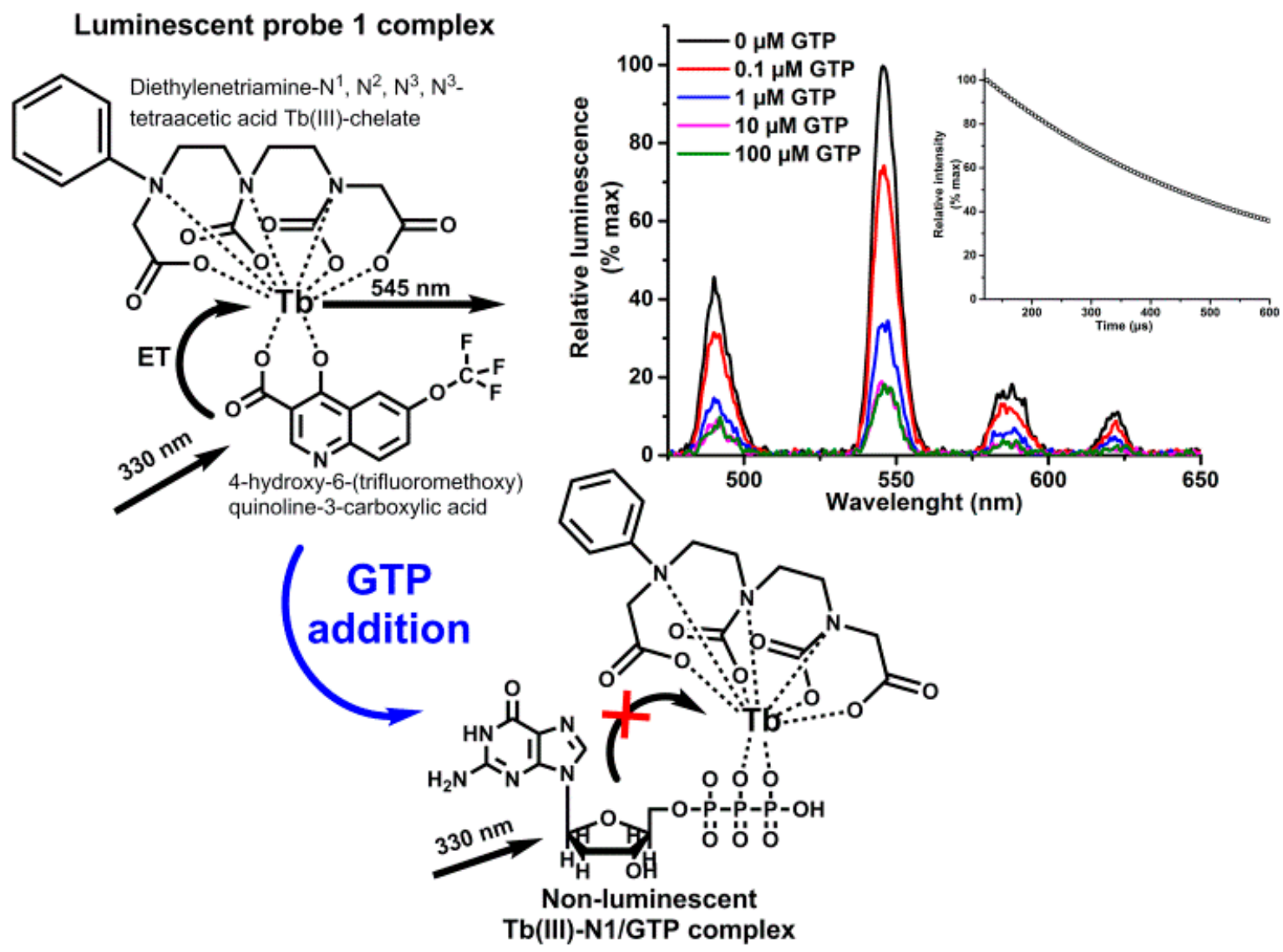

Figure 1. Apparent mode of action of the label-free nucleotide sensor. (A) Tb(III)-N1 forms a luminescent Probe 1 complex with antenna 1 in neutral or acidic aqueous solution. Addition of the phosphatecontaining molecule, such as GTP, induce competitive antenna 1 replacement from the complex, forming non-luminescent $\mathrm{Tb}$ (III)-N1/GTP complex. (B) Luminescence emission and decay measurements showed typical $\mathrm{Tb}(\mathrm{III})$-spectra and luminescent lifetime (inset) for Probe 1 ( $\mathrm{pH} 7$ ), responding negatively for increasing GTP concentration.

To sensitize $\mathrm{Tb}(\mathrm{III})$-ion luminescence, six different antenna molecules were first tested in the presence of different NTPs. All antennas (1o 6) sensitized $\mathrm{Tb}$ (III)-ion directly, but we found that complexes were sensitive to assay components such as enzymes and peptides (Table S1). Therefore, we selected 7-dentate $\mathrm{Tb}(\mathrm{III})-\mathrm{N} 1$-chelate as a ion carrier to provide kinetic and thermodynamic stability to the probe, and to minimize the interferences from other ions and assay components, even the ultimate sensitivity was slightly compromised. In the selected buffer ( $\mathrm{pH} 7)$, 4-hydroxy-6-(trifluoromethoxy)quinoline-3-carboxylic acid (antenna 1) showed the highest stability and robustness with relatively high signal-to-background ratio (S/B over 40). Also, nanomolar sensitivity for the sensor was observed when tested with or without GTP (Table S1, Figure S3). The antenna 1 and $\mathrm{Tb}$ (III)-N1-chelate complex was named as a Probe 1, used in all further assays. The ability of the Probe 1 to sense the number of phosphates was monitored with different phosphate containing anions. In a typical nucleotide titration, NTPs are detected in low nanomolar concentration, while nucleotide di- (NDP) and monophosphates (NMP) require 10 to 1000-fold higher concentrations, respectively (Figure 2a). For example, the limit-of-detection (LOD) for GTP, GDP, and GMP were $18.2 \pm 2.5 \mathrm{nM}, 197 \pm 42 \mathrm{nM}$, and $>15,000 \mathrm{nM}$, respectively. As expected, Probe 1 showed similar binding behavior independently of the nucleotide, solely separating the tested nucleotides by the number of phosphates. Cyclic nucleotides (cAMP and cGMP) were undetectable for the sensor. Phosphate dependence was further demonstrated by testing different polyphosphates, 
which quenched the luminescence in the following order $\left(\mathrm{NaPO}_{3}\right)_{\mathrm{n}}>\left(\mathrm{NaPO}_{3}\right)_{3}>\left(\mathrm{NaPO}_{3}\right)_{2}>>$ $\mathrm{Na}_{2} \mathrm{HPO}_{4}>\mathrm{NaH}_{2} \mathrm{PO}_{4}$ (Figure $2 \mathrm{~b}$ ). This further confirms the Probe 1 ability to monitor directly the number of phosphates. Table 2 summarizes the detection properties of the Probe 1 with different phosphate-containing molecules.

Table 2. Summary of the binding properties of the Probe 1 to different phosphate-containing anions ${ }^{a}$.

\begin{tabular}{cccc}
\hline Anion Species & $\mathbf{E C}_{\mathbf{5 0}}(\mathbf{n M})$ & LOD $(\mathbf{n M})$ & Linear Range $(\boldsymbol{\mu M})$ \\
\hline $\mathrm{ATP}$ & $107 \pm 0.5$ & $15.7 \pm 3.0$ & $0.02-5$ \\
$\mathrm{GTP}$ & $97 \pm 0.4$ & $18.2 \pm 2.5$ & $0.02-10$ \\
$\mathrm{CTP}$ & $17 \pm 0.2$ & $3.1 \pm 1.5$ & $0.01-1$ \\
$\mathrm{ITP}$ & $155 \pm 0.4$ & $43.6 \pm 5.7$ & $0.02-10$ \\
$\mathrm{UTP}$ & $164 \pm 0.7$ & $28.2 \pm 4.4$ & n.c. \\
$\mathrm{AMP}-\mathrm{PNP}$ & $73 \pm 0.6$ & $8.6 \pm 3.9$ & n.c. \\
$\mathrm{ADP}$ & $1170 \pm 70$ & $161 \pm 48$ & $0.2-150$ \\
$\mathrm{GDP}$ & $1110 \pm 60$ & $197 \pm 42$ & $0.2-100$ \\
$\mathrm{UDP}$ & $1540 \pm 70$ & $165 \pm 36$ & $0.2-150$ \\
$\mathrm{GMP}$ & $16,800 \pm 3900$ & n.c. & n.c. \\
$\left(\mathrm{NaPO}_{3}\right)_{\mathrm{n}}$ & $33 \pm 0.2$ & $13.6 \pm 7.2$ & n.c. \\
$\left(\mathrm{NaPO}_{3}\right)_{3}$ & $60 \pm 0.4$ & $15.5 \pm 2.6$ & n.c. \\
$\left(\mathrm{NaPO}_{3}\right)_{2}$ & $432 \pm 3$ & $69.3 \pm 20.2$ & n.c. \\
$\mathrm{Na}_{2} \mathrm{HPO}_{4}$ & $>250$ & n.c. & n.c. \\
$\mathrm{cGMP}_{\mathrm{cAMP}}$ & n.d. & n.d. & n.d. \\
$\mathrm{cAMP}$ & n.d. & n.d. & n.d.
\end{tabular}

a Experimental conditions: excitation $330 \mathrm{~nm}$, emission $545 \mathrm{~nm}$, delay $100 \mu \mathrm{s}$, decay $200 \mu \mathrm{s},[\mathrm{Tb}(\mathrm{III})-\mathrm{N} 1]=7.5 \mathrm{nM}$, [4-hydroxy-6-(trifluoromethoxy)quinoline-3-carboxylic acid] = 7.5 $\mu \mathrm{M}$, Assay buffer 1 [20 mM HEPES, pH 7, $1 \mathrm{mM}$ $\mathrm{MgCl}_{2}, 0.01 \%$ Triton-X 100, $0.005 \% \gamma$-globulins], error represents SD, $\mathrm{n}=3$ or $\mathrm{n}=5$. n.d. not detected. n.c. not calculated.

A

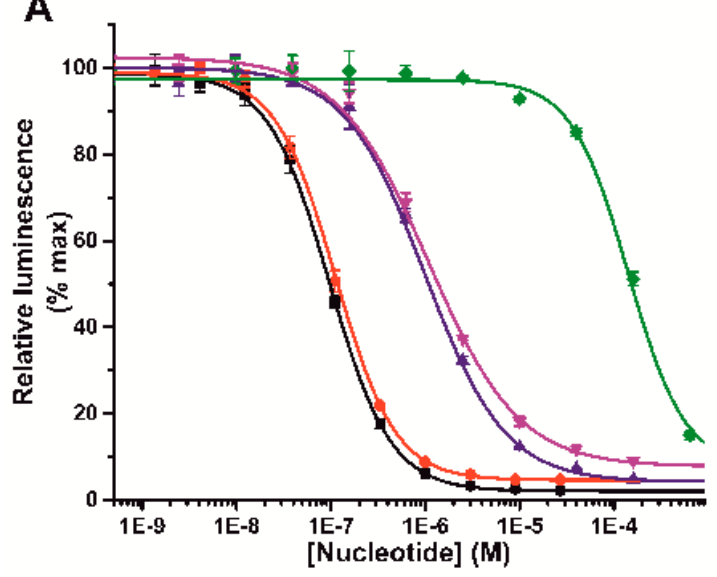

B

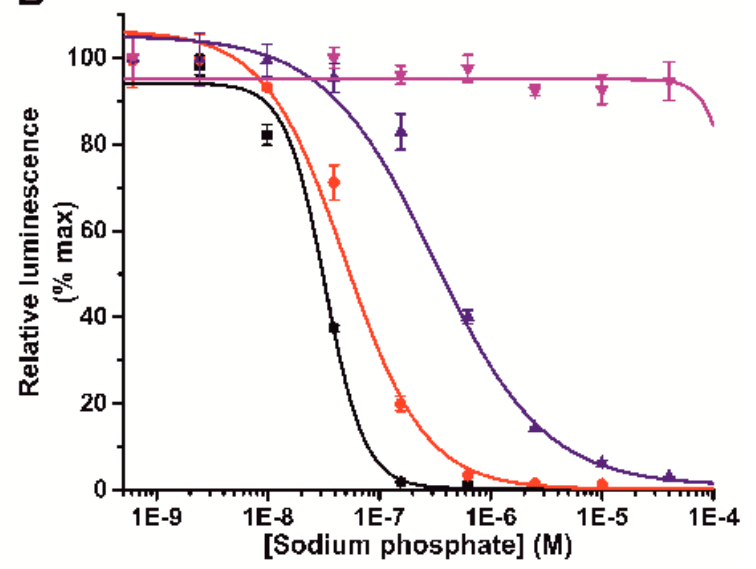

Figure 2. Time-gated $\mathrm{Tb}(\mathrm{III})$-luminescence response curves of Probe 1 with different phosphatecontaining molecules. (A) Probe 1 showed nanomolar nucleotide triphosphate detection sensitivity (GTP; black and ATP; red) and 10- to 1000-fold specificity over nucleotide di- and monophosphates (GDP; blue, ADP; magenta, and GMP; green), respectively. (B) Probe 1 detects sodium polyphosphates in similar phosphate number order as nucleotides, $\left(\mathrm{NaPO}_{3}\right)_{\mathrm{n}}$ (black) $>\left(\mathrm{NaPO}_{3}\right)_{3}($ red $)>\left(\mathrm{NaPO}_{3}\right)_{2}$ (blue) $>>\mathrm{Na}_{2} \mathrm{HPO}_{4}$ (magenta). Data represent mean $\pm \mathrm{SD}(\mathrm{n}=3)$.

\subsection{K-Ras Functionality Can Be Monitored at Nanomolar Sensitivity Similar to the Control Assay}

Thereafter, we applied the Probe 1 in biological applications to demonstrate the concept functionality. First, we studied Ras activity with probe 1, and these assays were performed side-by-side with the previously introduced QRET assays used as a reference [22,23]. These assays were selected to enable direct comparison in a same buffer and assay conditions. We started by monitoring GTPase cycling, using K-Ras as an active GTP hydrolyzing enzyme (Figure S4a). K-Ras is frequently mutated 
in various cancers, and these mutations impair GTP hydrolysis leading to constitutive activation of the K-Ras downstream signaling $[27,28]$. Thus, K-Ras is a highly attractive protein as a drug target. In the assay, a guanine nucleotide exchange factor (SOS $\left.{ }^{\mathrm{cat}}\right)$ and a GTPase activating proteins (NF1 or p120RasGAP) are required to catalyze GTP hydrolysis (Figure S4a). Only wild-type K-Ras, in comparison to the mutants (G12C, G12D, Q61L, and Q61R), showed increased luminescence due to the weaker luminescence quenching ability of GDP compared to GTP (Figure 3a, Figure S5). The functionality of the GTP hydrolysis assay was further tested by running a dose-response data on nucleotide exchange inhibitor (DCAI) [29]. This assay was also performed using previously described GTP-specific Fab-fragment based QRET assay (Figure 3b, Figure S6) [23,24]. In the assay with wild-type K-Ras, SOS cat, and p120RasGAP, the $\mathrm{IC}_{50}$ value monitored with DCAI and Probe 1 was $158 \pm 13 \mu \mathrm{M}$, and the observed S/B ratio was 4.5 (Figure 3b). The QRET assay gave an $\mathrm{IC}_{50}$ value of $199 \pm 8 \mu \mathrm{M}$ with the S/B of 5.1 (Figure S7). In either assay, no change in signal was observed with a hydrolysis dead Q61R K-Ras mutant. As DCAI was originally reported as a nucleotide exchange inhibitor, we monitored the $\mathrm{IC}_{50}$ values also with K-Ras and SOS ${ }^{\text {cat }}$ in a nucleotide exchange assay (Figure S4b), taking into account that the GTP bound to the K-Ras cannot anymore induce the $\mathrm{Tb}$ (III)-luminescence quenching. The $\mathrm{IC}_{50}$ value of $232 \pm 28 \mu \mathrm{M}(\mathrm{S} / \mathrm{B}=3.0$ ) was monitored with Probe 1 (Figure S8) and $233 \pm 22 \mu \mathrm{M}$ $(\mathrm{S} / \mathrm{B}=10.3)$ with $\mathrm{Eu}(\mathrm{III})$-GTP based QRET assay used as a reference method (Figure S9) [22,23]. The $\mathrm{IC}_{50}$ values measured for DCAI are similar to those reported previously [29].
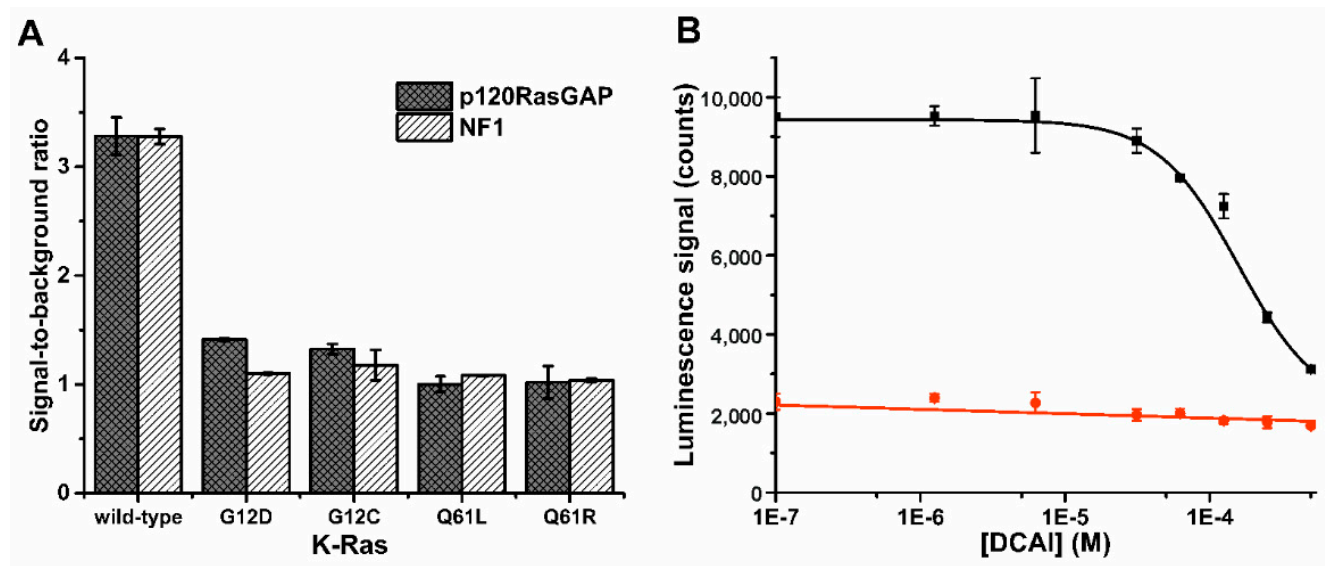

Figure 3. Time-gated $\mathrm{Tb}(\mathrm{III})$-luminescence monitoring of the K-Ras GTPase activities. (A) GTPase cycle of GDP-GTP exchange (SOS ${ }^{\text {cat }}$ ) and GTP hydrolysis (p120RasGAP or NF1) with wild-type K-Ras reduces GTP concentration increasing Probe 1 time-gated $\mathrm{Tb}(\mathrm{III})$-luminescence. This GTP hydrolysis in impaired with mutant $\mathrm{K}$-Ras proteins, which gave low $\mathrm{Tb}$ (III)-luminescence. (B) DCAI inhibits SOS ${ }^{\text {cat }}$ dependent GDP-GTP exchange and thus impairs GTP hydrolysis resulting Tb(III)-luminescence quenching with wild-type K-Ras (black), while no change in Q61R K-Ras mutant (red) signal were detected. Data represent mean \pm SD $(n=3)$.

\subsection{Probe 1 Enables Nucleotide Triphosphate Hydrolysis Monitoring to Di-and Further to Nucleotide Monophosphates}

Next, we assayed a panel of NTPs and NDPs with apyrase ATPase enzyme (Figure S4c). Apyrases are widely used tools in biotechnological applications, but they also possess important role in the maintenance of blood fluidity [30]. As a model, we selected potato apyrase and it was titrated at two fixed ATP concentration $(1 \mu \mathrm{M}$ or $10 \mu \mathrm{M})$ in the developed assay using Probe 1 (Figure $4 \mathrm{a}$ ). Increased Tb(III)-signal indicates efficient ATP hydrolysis under the used assay conditions (buffer 2, $\mathrm{pH}$ 6.5). As expected, no signal change was monitored with non-hydrolysable ATP analog, AMP-PNP. This highlighted the relation between signal change and enzymatic ATP hydrolysis. Within $50 \mathrm{~min}$ incubation, full ATP hydrolysis using $1 \mu \mathrm{M}$ and $10 \mu \mathrm{M}$ of ATP was achieved with $16 \mu \mathrm{U}$ (S/B 7.3) or $2 \mathrm{mU}$ (S/B 11.5) of apyrase, respectively. It is known that different apyrases have different specificity patterns for nucleotides [30]. Thus we tested the ATP specificity of the used apyrase by performing the 
hydrolysis reaction at single NTP $(10 \mu \mathrm{M})$ or NDP $(50 \mu \mathrm{M})$ concentration and with a nucleotide panel (ATP, GTP, UTP, CTP, AMP-PNP, ADP, GDP, and UDP). Apyrase showed a clear ATP specificity in the NTP titration (Figure 4b), and only minor hydrolysis was detected with UTP and GTP, without detectable hydrolysis of CTP or AMP-PNP. However, in the NDP hydrolysis assay the adenosine nucleotide preference was less clear, and also GDP and UDP were hydrolyzed to corresponding NMPs (Figure S10). The observations in specificity might be due to the used apyrase, which is a mixture of two different apyrase species with varying specificity patterns and buffer preferences [31,32].
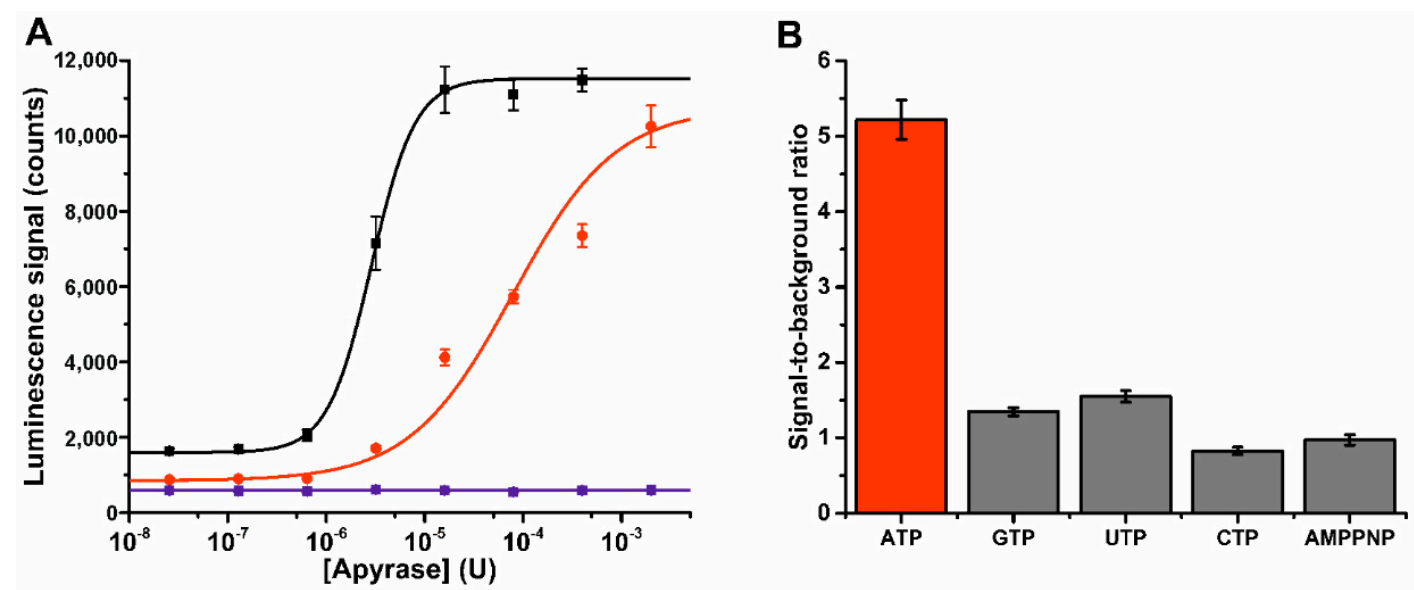

Figure 4. Time-gated $\mathrm{Tb}(\mathrm{III})$-luminescence monitoring of apyrase ATPase activities. (A) Apyrase was titrated in the presence or $1 \mu \mathrm{M}$ ATP (black), and $10 \mu \mathrm{M}$ ATP (red) or with $10 \mu \mathrm{M}$ AMP-PNP (blue), and ATPase activity was monitored from the increasing $\mathrm{Tb}(\mathrm{III})$-luminescence signal. (B) Apyrase $(50 \mu \mathrm{U})$ showed ATP specific hydrolysis activity, when assayed with $10 \mu \mathrm{M}$ nucleotide triphosphate (ATP, GTP, UTP, CTP, and AMP-PNP). Data represent mean \pm SD $(n=6)$.

Here we presented homogeneous label-free method for sensitive NTP detection using two NTP processing model enzyme systems, K-Ras and apyrase. There is a constant need for improved NTP sensing and especially ATP monitoring is of high importance. However, most of the current methods are not simple and convenient to use. This is mostly because of laborious assay protocols with multiple different detection components and incubation steps [9]. Now introduced label-free assay enables enzyme activity monitoring and detection of small molecules modulating the enzyme activity. Assays can be performed simply in two steps, by first performing the enzyme reaction and thereafter adding the detection components. Low material consumption and costs are achieved with $\mathrm{Tb}$ (III)-probe enabling time-gated monitoring and thus low background interferences. Now introduced label-free methods showed equal performance as the previously developed single-label QRET assays for K-Ras monitoring. $\mathrm{Tb}$ (III)-probe, however, enables more versatile assays compared to QRET, thus the assay principle is directly applicable to monitor different NTP related reactions with purified enzymes other than Ras. This was demonstrated with apyrase NTP and NDP hydrolysis assays. It is expected that the $\mathrm{Tb}$ (III)-probe can be used also to monitor reactions producing NTPs. Also, assay functionality with more complex matrixes is yet to be resolved.

\section{Conclusions}

In conclusion, we have developed a label-free luminescent $\mathrm{Tb}(\mathrm{III})$-probe for nucleotide polyphosphate detection with nanomolar sensitivity. The probe can distinguish NTPs from NDPs and NMPs in neutral aqueous solution, and the detection strategy was proved to be functional in monitoring of enzymatic activity of K-Ras and potato apyrase, and also in HTS compatible inhibitor studies. Probe 1 was shown to enable monitoring of highly relevant enzymatic reactions related to ATP and GTP biology, and thus it is expected to be suitable for a large variety of different reactions related to phosphate-containing molecules. 
Supplementary Materials: The following are available online at http:/ / www.mdpi.com/1424-8220/18/11/3989/ s1, Supplementary Figures S1-S10 and Table S1.

Author Contributions: The work presented in this paper was conducted in collaboration with all the authors. K.K., and H.H. provided the initial ideas. K.K., and T.S. performed major part of the laboratory work. D.R., M.A.-B., and M.H. contributed in K-Ras activity work. K.K., T.S., S.K., and H.H. designed the probes and performed the spectral characterization. K.K. wrote the manuscript together with all other authors.

Funding: This work and the APC was funded by the Academy of Finland [296225 and 296093]. This project was also funded in part with federal funds from the National Cancer Institute, National Institutes of Health (NIH), under Contract No. HHSN261200800001E.

Acknowledgments: The content of this publication does not necessarily reflect the views or policies of the Department of Health and Human Services, and the mention of trade names, commercial products, or organizations does not imply endorsement by the U.S. Government.

Conflicts of Interest: The authors declare the following competing financial interest(s): Kari Kopra and Harri Härmä have commercial interest to the quencher molecule through QRET Technologies Ltd.

\section{References}

1. Exton, J.H. Cell signalling through guanine-nucleotide-binding regulatory proteins (G proteins) and phospholipases. Eur. J. Biochem. 1997, 243, 10-20. [CrossRef] [PubMed]

2. Khakh, B.S.; Burnstock, G. The double life of ATP. Sci. Am. 2009, 301, 84-90, 92. [CrossRef] [PubMed]

3. Firoz, A.; Malik, A.; Joplin, K.H.; Ahmad, Z.; Jha, V.; Ahmad, S. Residue propensities, discrimination and binding site prediction of adenine and guanine phosphates. BMC Biochem. 2011, 12, 20. [CrossRef] [PubMed]

4. O'Dwyer, P.J.; King, S.A.; Hoth, D.F.; Leyland-Jones, B. Role of thymidine in biochemical modulation: A review. Cancer Res. 1987, 47, 3911-3919. [PubMed]

5. Lecca, D.; Ceruti, S. Uracil nucleotides: From metabolic intermediates to neuroprotection and neuroinflammation. Biochem. Pharmacol. 2008, 75, 1869-1881. [CrossRef] [PubMed]

6. Xu, Z.; Singh, N.J.; Lim, J.; Pan, J.; Kim, H.N.; Park, S.; Kim, K.S.; Yoon, J. Unique sandwich stacking of pyrene-adenine-pyrene for selective and ratiometric fluorescent sensing of ATP at physiological pH. J. Am. Chem. Soc. 2009, 131, 15528-15533. [CrossRef] [PubMed]

7. Nakano, S.; Fukuda, M.; Tamura, T.; Sakaguchi, R.; Nakata, E.; Morii, T. Simultaneous detection of ATP and GTP by covalently linked fluorescent ribonucleopeptide sensors. J. Am. Chem. Soc. 2013, 135, 3465-3473. [CrossRef] [PubMed]

8. Ng, S.; Lim, H.S.; Ma, Q.; Gao, Z. Optical aptasensors for adenosine triphosphate. Theranostics 2016, 6, 1683-1702. [CrossRef] [PubMed]

9. Khlyntseva, S.V.; Bazel, Y.R.; Vishnikin, A.B.; Andruch, V.J. Methods for the determination of adenosine triphosphate and other adenine nucleotides. J. Anal. Chem. 2009, 64, 657-673. [CrossRef]

10. Zhou, Y.; Xu, Z.; Yoon, J. Fluorescent and colorimetric chemosensors for detection of nucleotides, FAD and NADH: Highlighted research during 2004-2010. Chem. Soc. Rev. 2011, 40, 2222-2235. [CrossRef] [PubMed]

11. Comley, J. Kinase screening and profiling-spoilt for choice. Drug Discov. World 2006, 7, 27-50.

12. Hemmilä, I.; Dakubu, S.; Mukkala, V.-M.; Siitari, H.; Lövgren, T. Europium as a label in time-resolved immunofluorometric assays. Anal. Biochem. 1984, 137, 335-343. [CrossRef]

13. Maity, D.; Li, M.; Ehlers, M.; Schmuck, C. A metal-free fluorescence turn-on molecular probe for detection of nucleoside triphosphates. Chem. Commun. 2017, 53, 208-211. [CrossRef] [PubMed]

14. Li, S.-H.; Yuan, W.-T.; Zhu, C.-Q.; Xu, J.-G. Species-differentiable sensing of phosphate-containing anions in neutral aqueous solution based on coordinatively unsaturated lanthanide complex probes. Anal. Biochem. 2004, 331, 235-242. [CrossRef] [PubMed]

15. Hou, F.; Miao, Y.; Jiang, C. Determination of adenosine disodium triphosphate (ATP) using oxytetracycline-Eu3+ as a fluorescence probe by spectrofluorimetry. Spectrochim. Acta A Mol. Biomol. Spectrosc. 2005, 61, 2891-2895. [CrossRef] [PubMed]

16. Li, L.; Yang, J.; Wu, X.; Sun, C.; Liu, Y.; Liu, S.; Su, B. The fluorescence enhancement effect of Tb-Gd-adenosine triphosphate-phen system and its analytical application. Talanta 2005, 65, 201-205. [CrossRef] [PubMed]

17. Weitz, E.A.; Chang, J.Y.; Rosenfield, A.H.; Pierre, V.C. A selective luminescent probe for the direct time-gated detection of adenosine triphosphate. J. Am. Chem. Soc. 2012, 134, 16099-16102. [CrossRef] [PubMed] 
18. Martínez-Máñez, R.; Sancenón, F. Fluorogenic and chromogenic chemosensors and reagents for anions. Chem. Rev. 2003, 103, 4419-4476. [CrossRef] [PubMed]

19. Härmä, H.; Rozwandowicz-Jansen, A.; Martikkala, E.; Frang, H.; Hemmilä, I.; Sahlberg, N.; Fey, V.; Perälä, M.; Hänninen, P. A new simple cell-based homogeneous time-resolved fluorescence QRET technique for receptor-ligand interaction screening. J. Biomol. Screen. 2009, 14, 936-943. [CrossRef] [PubMed]

20. Martikkala, E.; Rozwandowicz-Jansen, A.; Hänninen, P.; Petäjä-Repo, U.; Härmä, H. A homogeneous single-label time-resolved fluorescence cAMP assay. J. Biomol. Screen. 2011, 16, 356-362. [CrossRef] [PubMed]

21. Martikkala, E.; Veltel, S.; Kirjavainen, J.; Rozwandowicz-Jansen, A.; Lamminmäki, U.; Hänninen, P.; Härmä, H. Homogeneous single-label biochemical Ras activation assay using time-resolved luminescence. Anal. Chem. 2011, 83, 9230-9233. [CrossRef] [PubMed]

22. Kopra, K.; Ligabue, A.; Wang, Q.; Syrjänpää, M.; Blaževitš, O.; van Adrichem, A.J.; Hänninen, P.; Veltel, S.; Abankwa, D.; Härmä, H. A homogeneous quenching resonance energy transfer assay for the kinetic analysis of the GTPase nucleotide exchange reaction. Anal. Bioanal. Chem. 2014, 406, 4147-4156. [CrossRef] [PubMed]

23. Kopra, K.; van Adrichem, A.J.; Salo-Ahen, O.M.H.; Peltonen, J.; Wennerberg, K.; Härmä, H. High-throughput dual screening method for Ras activities and inhibitors. Anal. Chem. 2017, 89, 4508-4516. [CrossRef] [PubMed]

24. Kopra, K.; Rozwandowicz-Jansen, A.; Syrjänpää, M.; Blaževitš, O.; Ligabue, A.; Veltel, S.; Lamminmäki, U.; Abankwa, D.; Härmä, H. GTP-specific fab fragment-based GTPase activity assay. Anal. Chem. 2015, 87, 3527-3534. [CrossRef] [PubMed]

25. Karhunen, U.; Jaakkola, L.; Wang, Q.; Lamminmäki, U.; Soukka, T. Luminescence switching by hybridization-directed mixed lanthanide complex formation. Anal. Chem. 2010, 82, 751-754. [CrossRef] [PubMed]

26. Zhao, Y.B.; Wang, D.Y.; Guo, X.Q.; Xu, J.G. Studies on the mechanism of fluorescence quenching of $\mathrm{Tb}^{3+}$-tiron complex by nucleotides, polynucleotides and nucleic acids. Chem. Res. Chin. Univ. 1997, 18, 691-695.

27. Vigil, D.; Cherfils, J.; Rossman, K.L.; Der, C.J. Ras superfamily GEFs and GAPs: Validated and tractable targets for cancer therapy? Nat. Rev. Cancer 2010, 10, 842-857. [CrossRef] [PubMed]

28. Fernandez-Medarde, A.; Santos, E. Ras in cancer and developmental diseases. Genes Cancer 2011, 2, 344-358. [CrossRef] [PubMed]

29. Maurer, T.; Garrenton, L.S.; Oh, A.; Pitts, K.; Anderson, D.J.; Skelton, N.J.; Fauber, B.P.; Pan, B.; Malek, S.; Stokoe, D.; et al. Small-molecule ligands bind to a distinct pocket in Ras and inhibit SOS-mediated nucleotide exchange activity. Proc. Natl. Acad. Sci. USA 2012, 109, 5299-5304. [CrossRef] [PubMed]

30. Smith, T.M.; Hicks-Berger, C.A.; Kim, S.; Kirley, T.L. Cloning, expression, and characterization of a soluble calcium-activated nucleotidase, a human enzyme belonging to a new family of extracellular nucleotidases. Arch. Biochem. Biophys. 2002, 406, 105-115. [CrossRef]

31. Kettlun, A.M.; Uribe, L.; Calvo, V.; Silva, S.; Rivera, J.; Mancilla, M.; Antonieta, M.; Valenzuela, M.A.; Traverso-Cori, A. Properties of two apyrases from Solanum tuberosum. Phytochemistry 1982, 21, 551-558. [CrossRef]

32. Kettlun, A.M.; Espinosa, V.; García, L.; Valenzuela, M.A. Potato tuber isoapyrases: Substrate specificity, affinity labeling, and proteolytic susceptibility. Phytochemistry 2005, 66, 975-982. [CrossRef] [PubMed]

(C) 2018 by the authors. Licensee MDPI, Basel, Switzerland. This article is an open access article distributed under the terms and conditions of the Creative Commons Attribution (CC BY) license (http:/ / creativecommons.org/licenses/by/4.0/). 